\title{
Flexible Bronchoscopic Removal of Push-Pin from Right Lower Lobe Bronchus: a Case Report
}

\author{
Prajowl Shresthal, Ashesh Dhungana ${ }^{1}$, Madhusudan Kayastha ${ }^{2}$, \\ Manisha Shrestha ${ }^{1}$, Deepa Niroula ${ }^{3}$
}

${ }^{1}$ National Academy of Medical Sciences (NAMS), Bir Hospital, Kathmandu, Nepal

${ }^{2}$ Kanti Children Hospital, Kathmandu, Nepal

${ }^{3}$ Kathmandu University School of Medical Sciences, Dhulikhel, Nepal

\section{ABSTRACT}

Foreign body aspiration is common in children and adolescents. Foreign body aspiration is often unnoticed and diagnosis may be delayed in children, as many fail to provide a history. Although rigid bronchoscopy is preferred modality, flexible bronchoscopy is also a useful tool for foreign body extraction from the distal airways in selected cases. An eleven-year-old boy presented with a history of fever and dry cough of one month's duration. A chest x-ray showed a linear radiopaque foreign body along the course of the right bronchus. Flexible bronchoscopy revealed a metallic nail-like structure in right lower lobe bronchus which was successfully grasped with the flexible forceps and extracted via the oral route with the bronchoscope. Upon extraction aspirated foreign body was found to be a push-pin.

Keywords: Flexible bronchoscopy; Foreign body; Push-pin; Radiopaque

\author{
Correspondence: \\ Dr. Prajowl Shrestha, MD, DM \\ Consultant Pulmonologist \\ Chest Unit, Department of Medicine \\ National Academy of Medical Sciences (NAMS), \\ Bir Hospital, Kathmandu, Nepal \\ ORCID ID: 0000-0003-1956-1142 \\ Email: prajwolaiims@gmail.com \\ Submitted: $26^{\text {th }}$ April 2020 \\ Accepted: $16^{\text {th }}$ June 2020 \\ Source of Support: None \\ Conflict of Interest: None \\ Citation: Shrestha P, Dhungana A, Kayastha M, \\ Shrestha M, Niroula D. Flexible bronchoscopic \\ removal of push-pin from right lower lobe bronchus: a \\ case report. NMJ 2020;3(1):323-5. DOI 10.3126/nmj. \\ v3i1.28613
}

\section{INTRODUCTION}

Foreign body aspiration is common in children and adolescents. ${ }^{1,2}$ It may present as acute respiratory failure, new-onset dyspnea, wheeze, cough, and hemoptysis requiring urgent removal. However, diagnosis is often delayed if a child failed to give a clear history of foreign body aspiration or has nonspecific symptoms. ${ }^{3}$ A high index of suspicion is required in cases that have nonspecific symptoms. Radiologically foreign bodies may present as atelectasis, non-resolving pneumonia, and localized bronchiectasis or sometimes incidentally detected in the chest radiograph. ${ }^{4}$ Here, we report a case of foreign body- a push pin in right lower lobe bronchus in a child who presented with fever and cough of one-month duration.

\section{CASE REPORT}

An eleven-year-old boy presented with a history of cough and fever for one month. The cough was dry without diurnal variation. Fever was low to moderate grade, not associated with chills and rigors. He denied any history of chest pain, hemoptysis, wheezing, and shortness of breath, or weight loss. His appetite was normal. On examination he was febrile, his pulse rate was $112 / \mathrm{min}$ 
regular, and respiratory rate was $14 / \mathrm{min}$. On chest examination, inspiratory crackles with bronchial breath sounds were heard over the right infrascapular area. Other systemic examinations were unremarkable. Upon evaluation, his white blood cell count was $14,600 / \mathrm{mm}^{3}$ with $80 \%$ neutrophils. His renal function and liver function were within normal limits. Chest x-ray (fig. 1) showed a well defined radiopaque linear opacity in the right pericardiac region along the course of the right bronchus. Distal to the opacity, inhomogeneous parenchymal infiltrates suggesting consolidation was seen. Diagnosis of foreign body aspiration, probably a metallic nail obstructing the distal right bronchial tree and post obstructive pneumonia of right lower lobe was made. History was reviewed again; however patient denied any history of foreign body aspiration in recent and remote past.

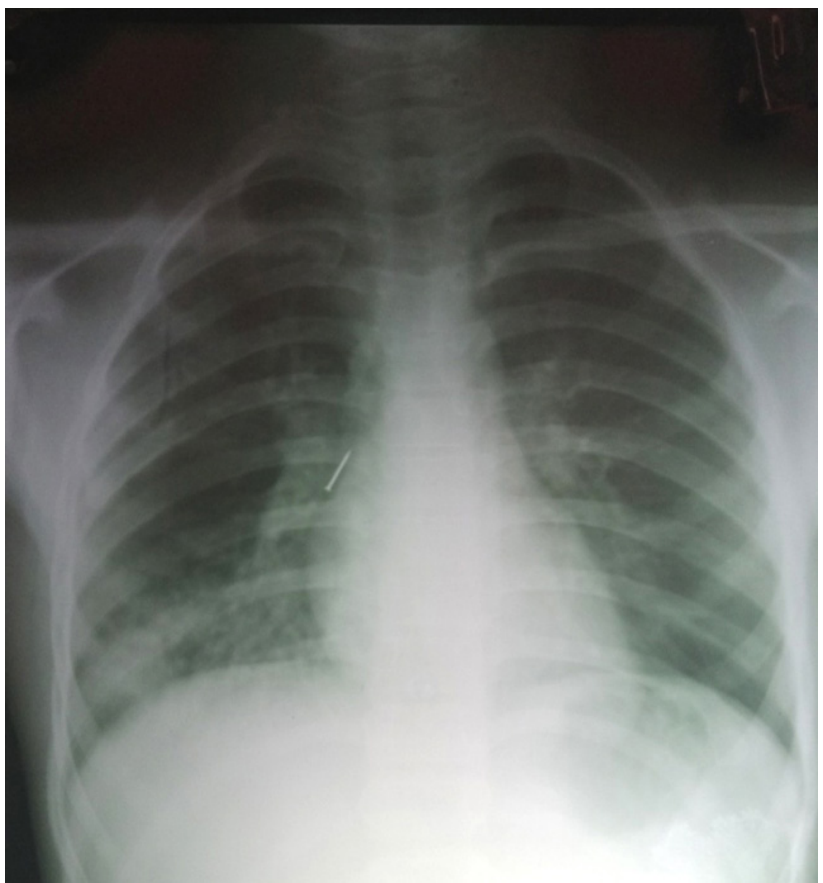

Figure 1: Chest x-ray (PA view) showing a linear hyperlucent opacity in the right pericardiac region along the course of right bronchus and right lower zone consolidation

Flexible bronchoscopy was done via an oral route under deep sedation with intravenous midazolam, fentanyl, and propofol. Lignocaine ( $2 \%$ ) was used for airway anesthesia as per sprayas you-go technique. A metallic nail-like structure was seen in the right lower lobe bronchus (fig. 2A). It was impacted at the opening of lower lobe bronchus completely obstructing it. An initial attempt was made to extract the foreign body using a basket. However, it failed, as the basket could not be negotiated distal to the foreign body. Hence an attempt to grasp the tip of the nail using a rat-tooth forceps was made. The forceps was advanced into the site of the nail and the tip was firmly grasped (fig. 2B). Then it was pulled out en-bloc along with bronchoscope.

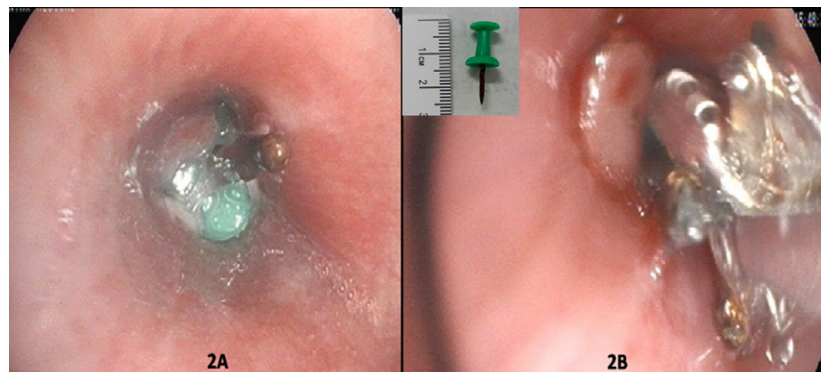

Figure 2: Bronchoscopic image. 2A: Metallic foreign body lodged in right lower lobe bronchus. 2B: Foreign body grasped with biopsy forceps. Inset showing the extracted push-pin.

Upon extraction, the aspirated foreign body was found to be a push-pin (fig 2, inset) lodged in an upside-down position. Following the removal of the pushpin, purulent secretions were seen coming from the right lower lobe. Bronchial toileting was done and the scope was taken out subsequently.

The patient remained stable throughout the procedure. After the procedure, the patient was admitted in the ward, a broad-spectrum antibiotic was initiated because of the right lower lobe post obstructive pneumonia. A repeat chest x-ray done after 24 hours showed a significant resolution of right lower zone consolidation (fig3). The patient became afebrile 48 hours after the procedure and subsequently discharged in a stable condition.

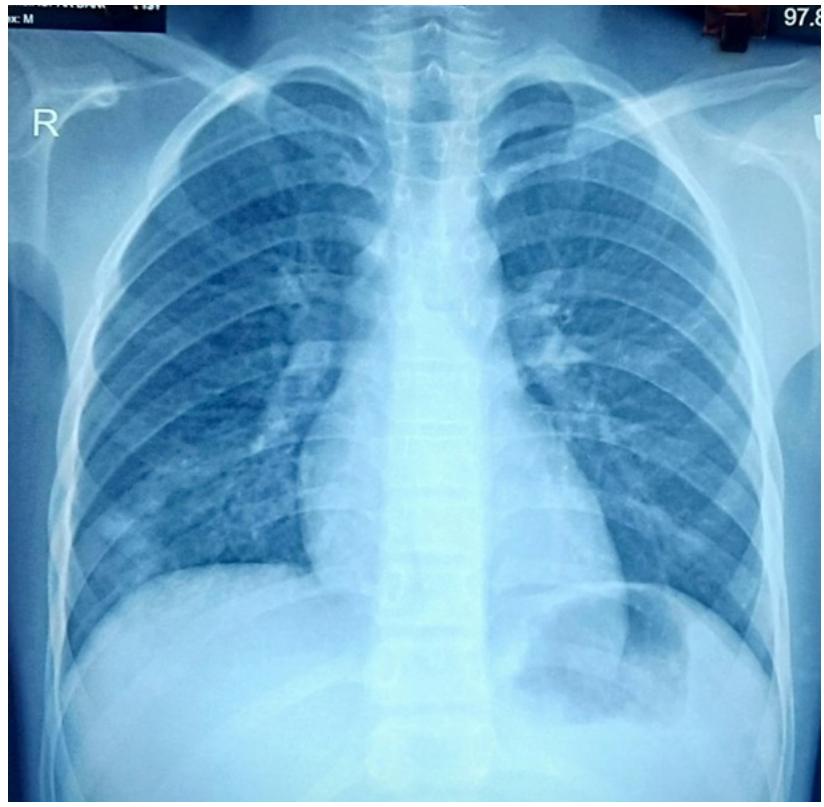

Figure 3: Chest $x$-ray (PA view) after bronchoscopy showing significant resolution of right lower zone consolidation and absence of foreign body

\section{DISCUSSION}

Foreign body aspiration may go unrecognized and diagnosis is often delayed in children and adolescents who fail to give a history of choking and aspiration. ${ }^{5}$ A high index of suspicion is required in an appropriate clinical setting. Diagnosis is usually confirmed by radiology and flexible bronchoscopy. If the aspirated foreign body remains undetected, and diagnosis is delayed, complications especially post obstructive pneumonia, bronchiectasis and bronchial stenosis may occur causing significant morbidity. ${ }^{6}$ The majority of aspirated foreign bodies in children are organic, reported up to $91 \%$; however, it varies in different studies depending upon the 
lifestyle and eating habits. ${ }^{1}$ Foreign bodies are generally lodged in more proximal parts of the tracheobronchial tree in children as compared to adults. ${ }^{7,8}$ In our case, the aspirated foreign body was a push-pin which was lodged in right lower lobe bronchus due to its small size. In the case of proximal obstruction, patients become symptomatic immediately. They usually present with excessive cough, choking, dyspnea, and cyanosis which may sometimes be life threatening. ${ }^{9}$ Thus, proximal obstruction warrants immediate removal, preferably with a rigid bronchoscope under general anesthesia. In our case, the aspirated push-pin was lodged in right lower lobe bronchus, hence it went unnoticed and the onset of symptoms was delayed. Flexible bronchoscopic removal was considered because of its distal anatomical location.

Almost all patients with an aspirated foreign body require bronchoscopy as a diagnostic and therapeutic tool. Rigid bronchoscopy is the first choice for the removal of tracheobronchial foreign bodies which are lodged in central airways. Owing to its larger working channel and good airway control rigid bronchoscopy under general anesthesia remains the procedure of choice. ${ }^{10}$ However, recent years has seen increased utilization of flexible bronchoscopy for this purpose. ${ }^{11-13}$ The overall success rate of the flexible bronchoscopy has been reported up to $80 \%$, warranting an initial flexible bronchoscopic assessment for the feasibility of foreign body removal before proceeding with rigid bronchoscopy or surgery. ${ }^{13}$ The advantages of flexible bronchoscopy are many; it requires less sedation, it is easy to perform and more importantly, it is readily available at most centers. However, caution must be taken while attempting to remove large and long-standing foreign bodies as there may be bleeding or dislodgement. The narrow suction channel, poor airway control, and obscured vision are major limitations of a flexible bronchoscope. A rigid bronchoscope should always be at standby while dealing with such cases and rigid bronchoscopy should be done if flexible bronchoscopy fails. In our case, aspirated foreign body, a push-pin was present in the peripheral bronchus in an upside-down position and there was no significant granulation tissue and the risk of bleeding was less. We were able to grasp the tip of the pin with the biopsy forceps and pull it out en-bloc with bronchoscope leading to successful flexible bronchoscopic retrieval.

This case report highlights the usefulness of flexible bronchoscopy in foreign body extraction that are lodged in the distal airways, thus avoiding more complicated procedures like rigid bronchoscopy and surgery.

\section{CONCLUSIONS}

Flexible bronchoscopy is a useful therapeutic modality for the extraction of a foreign body located in the distal airway. The success of flexible bronchoscopy depends upon case selection. It helps to avoid more complicated procedures like rigid bronchoscopy and surgery in selected cases.

\section{REFERENCES}

1. Baharloo F, Veyckemans F, Francis C, Biettlot MP, Rodenstein DO. Tracheobronchial foreign bodies: presentation and management in children and adults. Chest 1999;115(5):1357-62. Crossref

2. Asif M, Shah SA, Khan F, Ghani R. Analysis of tracheobronchial foreign bodies with respect to sex, age, type and presentation. $\mathrm{J}$ Ayub Med Coll Abbottabad. 2007;19 (1):13-5. Website

3. Metrangelo S, Monetti C, Meneghini L, Zadra N, Giusti F. Eight years' experience with foreign body aspiration in children: what is really important for a timely diagnosis? J Pediatr Surg. 1999;34:1229-31. Crossref

4. Zissin R, Shapiro-Feinberg M, Rozenman J, Apter S, Smorjik J, Hertz M. CT findings of the chest in adults with aspirated foreign bodies. Eur Radiol. 2001;11(4):606-11. doi:10.1007/s003300000619

5. Hilliard T, Sim R, Saunders M, Langton Hewer S, Henderson J. Delayed diagnosis of foreign body aspiration in children. Emerg Med J. 2003;20: 100 -1. $\underline{\text { Crossref }}$

6. Oğuz F, Citak A, Unüvar E, Sidal M. Airway foreign bodies in childhood. Int J Pediatr Otorhinolaryngol. 2000;52:11-6. Crossref

7. Dong Y-C, Zhou G-W, Bai C, Huang H-D, Sun Q-Y, Huang Y, et al. Removal of tracheobronchial foreign bodies in adults using a flexible bronchoscope: experience with 200 cases in China. Intern Med. 2012;51(18):2515-9. Crossref
8. Goyal R, Nayar S, Gogia P, Garg M. Extraction of tracheobronchial foreign bodies in children and adults with rigid and flexible bronchoscopy. J Bronchology Interv Pulmonol. 2012;19(1):35-43. $\underline{\text { Crossref }}$

9. Brkic F, Umihanic S, Altumbabic H, Ramas A, Salkic A, Umihanic $\mathrm{S}$, et al. Death as a consequence of foreign body aspiration in children. Med Arch. 2018;72 (3):220-3. Crossref

10. Korlacki W, Korecka K, Dzielicki J. Foreign body aspiration in children: diagnostic and therapeutic role of bronchoscopy. Pediatr Surg Int. 2011;27(8):833-7. Crossref

11. Boyd M, Watkins F, Singh S, Haponik E, Chatterjee A, Conforti J, et al. Prevalence of flexible bronchoscopic removal of foreign bodies in the advanced elderly. Age Ageing. 2009;38(4):396-400. Crossref

12. Sehgal IS, Dhooria S, Ram B, Singh N, Aggarwal AN, Gupta D, et al. Foreign body inhalation in the adult population: Experience of 25,998 bronchoscopies and systematic review of the literature. Respir Care. 2015;60(10):1438-48. Crossref

13. Rodrigues AJ, Oliveira EQ, Scordamaglio PR, Gregório MG, Jacomelli M, Figueiredo VR. Flexible bronchoscopy as the firstchoice method of removing foreign bodies from the airways of adults. J Bras Pneumol.2012;38(3):315-20. Crossref 